\title{
Diagnostic Value of Serum Ascites Lipid Gradients in Patients with Ascites
}

\section{Khairy H Morsy ${ }^{1 *}$, Mohamed AA Ghaliony ${ }^{2}$, Hamdy S Mohamed ${ }^{3}$ and Tarek TH EIMelegy ${ }^{4}$}

${ }^{1}$ Tropical Medicine and Gastroenterology Department, Faculty of Medicine, Sohag University, Egypt

${ }^{2}$ Tropical Medicine and Gastroenterology Department, Faculty of Medicine, Assiut University, Egypt

${ }^{3}$ Internal Medicine Department, Faculty of Medicine, Sohag University, Egypt

${ }^{4}$ Clinical Pathology Department, Faculty of Medicine, Assiut University, Egypt

\begin{abstract}
Introduction: Differential diagnosis of ascites is a common clinical problem.

Aim of the work: To study the value of Serum Ascites Lipid Gradients (SALG) of total cholesterol, triglyceride, HDL cholesterol, and LDL cholesterol in the diagnosis of ascites.

Materials and methods: The study was conducted on patients with ascites admitted to Tropical Medicine and Gastroenterology Department, Assiut University. The study included 115 patients with ascites of different etiologies (liver cirrhosis, tuberculosis, and malignant ascites). Clinical evaluation, abdominal ultrasonography, and laboratory investigations were conducted as follows: Serum Ascites Albumin Gradient (SAAG), serum lipid profile, and SALG of total cholesterol, triglyceride, HDL cholesterol, and LDL cholesterol.

Results: SAAG values were $1.87 \pm 0.537(>1.1), 0.58 \pm 0.112(<1.1)$, and $0.69 \pm 0.201(<1.1) \mathrm{gm} / \mathrm{dL}$ respectively for patients with liver cirrhosis, tuberculosis, and malignancy. The SALG levels for differentiating high SAAG (cirrhosis) from low SAAG (tuberculosis and malignancy) were $97.9 \pm 28.6$ versus $52.7 \pm 32.35$ and $49.4 \pm 28.64$ for SALG- total cholesterol, $74.7 \pm 28.2$ versus $56.9 \pm 48.0$ and $48.3 \pm 29.23$ for SALG- triglyceride, $28.67 \pm 9.11$ versus $18.53 \pm 15.7$ and $14.7 \pm 14.8$ for SALG- HDL cholesterol, $55.7 \pm 26.1$ versus $17.93 \pm 38.5$ and $28.5 \pm 13.65$ for SALGLDL cholesterol respectively. These values are significantly higher in cirrhosis than tuberculosis or malignancy. The cut-off SALG values being $67 \mathrm{mg} \%, 66 \mathrm{mg} \%, 26$ and $49 \mathrm{mg} \%$ in cholesterol, triglyceride, HDL cholesterol, LDL cholesterol respectively in differentiating cirrhotic ascites from tuberculosis or malignant ascites A close relationship between the levels of SALG and severity of cirrhosis is found but it is not significant.
\end{abstract}

Conclusion: SALG has important value in differentiation cirrhotic ascites from tuberculosis or malignant ascites but cannot differentiate tuberculosis ascites from malignant ascites.

Keywords: Cirrhosis; Ascites; Serum Ascites Albumin Gradient (SAAG); Serum Ascites Lipid Gradient (SALG); Tuberculosis; Malignancy

Abbreviations: SALG: Serum Ascites Lipid Gradients; SAAG: Serum Ascites Albumin Gradient

\section{Introduction}

Ascites is a common clinical complication of different diseases. The commonest cause of ascites is liver cirrhosis (80\%) followed by peritoneal malignancy (10\%), tuberculous peritonitis (2\%), congestive cardiac failure, nephrotic syndrome, and others (3\%) [1,2]. Various parameters like ascitic fluid physical examination, cell count, total protein concentration, Serum Ascitic Fluid Albumin Gradient [SAAG], cytology, cholesterol, amylase, lactic acid dehydrogenase, adenosine deaminase, and fibronectin levels have been used to differentiate exudative (ascitic fluid total protein $>2.5 \mathrm{gm} \%$ ) and transudative (ascitic fluid total protein $\leq 2.5 \mathrm{gm} \%$ ) ascites of different etiologies [3-21]

The physiologically based approach to classify ascites by Serum Ascites Albumin Gradient (SAAG) has completely replaced the traditional way of classification as transudate and exudate $[4,8,9]$. A high albumin gradient ( $\geq 1.1 \mathrm{gm} \%$ ) is usually associated with increased portal pressure as in cirrhosis and a low gradient $(<1.1 \mathrm{gm} \%)$, in conditions where ascites is not related to portal hypertension, but due to peritoneal cause as in peritoneal malignancy, tuberculous peritonitis, metastatic peritoneal deposits $[4,9,22]$. In patients with low albumin gradient the ability to differentiate malignant ascites from other etiologies is a major problem. Although ascitic fluid cytology is considered as a gold standard for malignancy, its diagnostic sensitivity is only $64 \%$ [23].

Some studies have proved an increased ascitic fluid cholesterol levels in patients with malignant ascites. Along with it, Serum Ascites Cholesterol Gradient (SACG) aids in differential diagnosis of ascites [23-25]. Few studies have related the serum \& ascitic fluid -total protein, albumin, cholesterol \& their gradients (SAAG, SACG) in differential diagnosis of ascites.

\section{Aim}

To study the value of Serum Ascites Lipid Gradients (SALG) of total cholesterol, triglyceride, HDL cholesterol, and LDL cholesterol in the diagnosis of ascites.

\section{Materials and Methods}

This study was hospital based, prospective, cross sectional analytic

${ }^{*}$ Corresponding author: Khairy Hammam Morsy, Tropical Medicine and Gastroenterology Department, Faculty of Medicine, Sohag University, Egypt, Tel: 01143292343; E-mail: khairy.morsy@yahoo.com

Received July 31, 2014; Accepted September 17, 2014; Published September 24,2014

Citation: Morsy KH, Ghaliony MAA, Mohamed HS, ElMelegy TTH (2014) Diagnostic Value of Serum Ascites Lipid Gradients in Patients with Ascites. J Liver 3: 165. doi:10.4172/2167-0889.1000165

Copyright: @ 2014 Morsy KH, et al. This is an open-access article distributed unde the terms of the Creative Commons Attribution License, which permits unrestricted use, distribution, and reproduction in any medium, provided the original author and source are credited. 
one. The study was carried out on patients with ascites admitted to Tropical Medicine and Gastroenterology Department, Assiut University Hospital during the period from June, 2012 to December, 2012. The study included 115 patients of ascites of different etiologies - 80 patients with liver cirrhosis, 20 patients with tuberculosis, and 15 patients with malignant ascites (7 gastrointestinal neoplasms, 4 mesothelioma, and 4 ovarian cancers).

Patients with spontaneous bacterial peritonitis, cirrhosis with hepatocellular carcinoma, ascites due to other etiologies such as nephrotic syndrome, mixed causes of ascites (cirrhosis with tuberculosis, cirrhosis with malignancy) were excluded from the study.

All patients were subjected to:

1. Clinical evaluation (medical history and physical examination).

2. Abdominal ultrasonographic examination.

3. Liver function tests (serum levels of total and direct bilirubin, albumin, alanine aminotransferase, aspartate aminotransferase, and alkaline phosphatase)

4. Prothrombin time estimation.

5. Serum lipid profile.

6. Ascitic lipid profile and ascitic fluid albumin.

7. Complete blood count.

8. Other investigations that may be helpful in diagnosis the cause of ascites (if needed) as: GIT endoscopies, laparoscopy, ascitic fluid culture, cytology, CT abdomen, erythrocyte sedimentation rate estimation.

Twelve hours-fasting blood and ascitic fluid samples were simultaneously collected under aseptic technique from all patients. Venous blood samples were allowed to clot in Wassermann tubes, sera were obtained by centrifugation. Ascitic fluid samples were collected by paracentesis (details), centrifuged and supernatants were separated into new Wassermann's tubes. Albumin, cholesterol, triglycerides, HDL levels were measured in sera and ascitic fluid supernatants using automated analyzer (Dimension clinical chemistry system, Siemens Healthcare Diagnostics Inc, USA). VLDL and LDL values were calculated using Friedewald formula [26]. Then, serum-ascites gradients for albumin and lipids were calculated using the formula: "Serumascites $\mathrm{X}$ gradient $=\mathrm{X}$ concentration in serum - $\mathrm{X}$ concentration in ascitic fluid", where X refers to the substance of interest (e.g., albumin or lipids).

\section{Ethical Aspects}

Before enrollment in the study, all participants signed a consent certificate. Before signing, they were able to discuss in details with the investigator certificate subjects and the study aim. Participants were clearly informed that refusing to participate in the study will not affect having full benefit from available medical service and treatment.

Data were collected by personal interview with participants taking in consideration data confidentiality. The study was approved by the Faculty of Medicine Ethical Committee -Assiut University.

\section{Statistical Analysis}

Statistical analysis was performed using Statistical Package for the Social Sciences (SPSS- version 17). All data was expressed as mean \pm $\mathrm{SD}$ or frequencies. For statistical evaluation, Student T test was used. Significance was accepted at $\mathrm{p}<0.05$.

\section{Results}

Demographic, clinical, and laboratory characteristics of patients with ascites are shown in Table 1. The study included 115 patients of ascites of different etiologies -80 patients with liver cirrhosis (59 male and 21 female), 20 patients with tuberculosis ( 7 male and 13 female), and 15 patients with malignant ascites ( 11 male and 4 female).

Ascitic fluid Total protein and Ascitic fluid Albumin levels of cirrhotic group are significantly lower than Tuberculosis or malignant group. Serum Ascites Albumin Gradient (SAAG) of cirrhotic group is significantly higher than Tuberculosis or malignant group as shown in Table 2.

Serum lipid profile (T.cholesterol, TG, HDL, and LDL) decreases significantly in cirrhotic patients with ascites than Tuberculosis or malignant group but no significant difference between Tuberculosis and malignant group as shown in Table 3.

Ascitic fluid lipid profile (T.cholesterol, TG, HDL, and LDL) decreases significantly in cirrhotic patients than Tuberculosis or malignant group but no significant difference between Tuberculosis and malignant group as shown in Table 4.

Serum Ascites lipid gradient (T.cholesterol, TG, HDL, and LDL) levels are significantly higher in cirrhotic patients than Tuberculosis or malignant group but no significant difference between Tuberculosis and malignant group as shown in Table 5 .

The levels of SALG correlate with severity of cirrhosis (Childs grade) but without statistically significant difference as shown in Tables 6 and 7.

\section{Discussion}

Many diseases are complicated by ascites. The most common cause of ascites is portal hypertension; secondary to liver cirrhosis, but in about $20 \%$ of cases there is an extrahepatic cause and $5 \%$ have more than one cause of ascites (mixed) - usually cirrhosis with either tuberculosis or malignancy [27].

Serum Ascites Albumin Gradient (SAAG) was adopted as a newer

\begin{tabular}{|c|c|c|c|}
\hline Characteristics & $\begin{array}{c}\text { Cirrhosis } \\
(n=80)\end{array}$ & $\begin{array}{c}\text { Tuberculosis } \\
(n=20)\end{array}$ & $\begin{array}{l}\text { Malignancy } \\
\quad(n=15)\end{array}$ \\
\hline $\operatorname{Sex}(M / F)$ & $59 / 21$ & $7 / 13$ & $11 / 4$ \\
\hline Age (years) & $46.5 \pm 6.9$ & $29.8 \pm 6.5$ & $58.2 \pm 8.4$ \\
\hline BMI & $22.0 \pm 3.2$ & $24.8 \pm 4.1$ & $18.5 \pm 2.6$ \\
\hline Jaundice on admission, $\mathrm{N}(\%)$ & $62(77.5 \%)$ & $1(5 \%)$ & $0(0 \%)$ \\
\hline Hepatomegaly, N (\%) & $11(13.75 \%)$ & $0(0 \%)$ & $1(6.6 \%)$ \\
\hline Splenomegaly, N (\%) & $50(62.5 \%)$ & $0(0 \%)$ & $0(0 \%)$ \\
\hline Abdominal masses, $\mathrm{N}(\%)$ & $0(0 \%)$ & $2(10 \%)$ & $1(6.6 \%)$ \\
\hline \multicolumn{4}{|l|}{$\begin{array}{l}\text { Laboratory data on } \\
\text { admission: }\end{array}$} \\
\hline Serum hemoglobin $(\mathrm{g} / \mathrm{dL})$ & $9.3 \pm 3.1$ & $12.2 \pm 2.4$ & $10.8 \pm 5.2$ \\
\hline Total bilirubin (umol/L) & $50.52 \pm 10.9$ & $9.8 \pm 1.6$ & $10.2 \pm 1.8$ \\
\hline Serum albumin (g/dL) & $2.87 \pm 0.6$ & $3.35 \pm 0.9$ & $3.62 \pm 0.7$ \\
\hline Serum ALT (IU/L) & $54.9 \pm 10$ & $33.8 \pm 8$ & $40.2 \pm 3$ \\
\hline Serum AST (IU/L) & $46.6 \pm 12$ & $35.3 \pm 9$ & $34.9 \pm 10$ \\
\hline Prothrombin time (seconds) & $15.8 \pm 3.8$ & $12.5 \pm 2.1$ & $13.7 \pm 2.9$ \\
\hline Serum creatinine (umol/L) & $101.3 \pm 4$ & $99 \pm 9$ & $100 \pm 6$ \\
\hline Serum sodium (mEq/L) & $140.3 \pm 2$ & $140.3 \pm 2$ & $140.3 \pm 2$ \\
\hline Platelets count (X 109u/L) & $116.04 \pm 12.93$ & $216.06 \pm 11.35$ & $166.08 \pm 9.83$ \\
\hline
\end{tabular}

BMI: Body Mass Index

Table 1: Demographic, Clinical, and Laboratory characteristics of patients with ascites. 
Citation: Morsy KH, Ghaliony MAA, Mohamed HS, EIMelegy TTH (2014) Diagnostic Value of Serum Ascites Lipid Gradients in Patients with Ascites. J Liver 3: 165. doi:10.4172/2167-0889.1000165

Page 3 of 5

\begin{tabular}{|c|c|c|c|c|c|c|}
\hline Parameter & Cirrhosis $(n=80)$ & Tuberculosis $(n=20)$ & Malignancy $(n=15)$ & $P^{1}$-value & $\mathbf{P}^{2}$-value & $P^{3}$-value \\
\hline $\begin{array}{c}\text { Ascitic fluid } \\
\text { Total protein (g/dl) }\end{array}$ & $1.5 \pm 0.58$ & $3.59 \pm 0.96$ & $4.49 \pm 0.78$ & $0.02^{*}$ & $0.01^{*}$ & 0.184 \\
\hline $\begin{array}{l}\text { Ascitic fluid } \\
\text { Albumin (g/dl) }\end{array}$ & $1.02 \pm 0.37$ & $2.85 \pm 0.74$ & $2.931 \pm 0.43$ & $0.034^{*}$ & $0.024^{*}$ & 0.321 \\
\hline $\begin{array}{c}\text { Serum Ascites } \\
\text { Albumin Gradient }(\mathrm{g} / \mathrm{dl})\end{array}$ & $1.87 \pm 0.537(>1.1)$ & $0.58 \pm 0.112(<1.1)$ & $0.69 \pm 0.201(<1.1)$ & $0.004^{*}$ & $0.003^{*}$ & 0.082 \\
\hline
\end{tabular}

$P^{1}$-value: Cirrhosis versus tuberculosis.

$\mathrm{P}^{2}$-value: Cirrhosis versus malignancy.

$\mathrm{P}^{3}$-value: Tuberculosis versus malignancy.

* Statistically significant: $p$ value $<0.05$.

Table 2: Ascitic fluid total protein, albumin, and Serum Ascites Albumin Gradients.

\begin{tabular}{|c|c|c|c|c|c|c|}
\hline Lipid profile & Cirrhosis $(n=80)$ & Tuberculosis $(n=20)$ & Malignancy $(n=15)$ & $\mathbf{P}^{1}$-Value & $P^{2}$-value & $\mathbf{P}^{3}$-Value \\
\hline T.Cholesterol (mg/dL) & $132.9 \pm 38.3$ & $164.8 \pm 44.2$ & $147.6 \pm 48.3$ & $0.004^{*}$ & $0.034^{*}$ & 0.842 \\
\hline Triglycerides (mg/dL) & $98.6 \pm 29.1$ & $141.4 \pm 58.6$ & $122.2 \pm 32.2$ & $0.014^{*}$ & $0.02^{*}$ & 0.341 \\
\hline HDL $(\mathrm{mg} / \mathrm{dL})$ & $32.5 \pm 10.7$ & $43.9 \pm 11.3$ & $46.9 \pm 9.6$ & $0.002^{*}$ & $0.004^{*}$ & 0.925 \\
\hline LDL (mg/dL) & $78.3 \pm 20.8$ & $93.9 \pm 31.5$ & $85.7 \pm 25.3$ & $0.00^{*}$ & $0.00^{*}$ & 0.812 \\
\hline
\end{tabular}

Lipid profile expressed by mean \pm SD

$\mathrm{P}^{1}$-value: Cirrhosis versus tuberculosis.

$\mathrm{P}^{2}$-value: Cirrhosis versus malignancy.

$\mathrm{P}^{3}$-value: Tuberculosis versus malignancy.

* Statistically significant: $p$ value $<0.05$.

Table 3: Serum lipid profile among patients with ascites.

\begin{tabular}{|c|c|c|c|c|c|c|}
\hline Parameter & Cirrhosis $(n=80)$ & Tuberculosis $(n=20)$ & Malignancy $(n=15)$ & $\mathbf{P}^{1}$-value & $\mathbf{P}^{2}$-value & $\mathbf{P}^{3}$-value \\
\hline T.Cholesterol (mg/dL) & $32.14 \pm 14.2$ & $110.6 \pm 29.0$ & $106.9 \pm 28.0$ & $0.002^{*}$ & $0.001^{*}$ & 0.961 \\
\hline Triglycerides (mg/dL) & $29.9 \pm 15.24$ & $78.65 \pm 38.0$ & $75.51 \pm 14.34$ & $0.005^{*}$ & $0.002^{*}$ & 0.813 \\
\hline HDL (mg/dL) & $7.79 \pm 3.67$ & $24.5 \pm 12.3$ & $29.9 \pm 15.33$ & $0.000^{*}$ & $0.002^{*}$ & 0.756 \\
\hline LDL (mg/dL) & $19.9 \pm 11.0$ & $76.6 \pm 32.58$ & $57.5 \pm 27.76$ & $0.000^{*}$ & $0.000^{*}$ & 0.092 \\
\hline
\end{tabular}

$\mathrm{P}^{1}$-value: Cirrhosis versus tuberculosis.

$\mathrm{P}^{2}$-value: Cirrhosis versus malignancy.

$\mathrm{P}^{3}$-value: Tuberculosis versus malignancy.

* Statistically significant: $p$ value $<0.05$.

Table 4: Ascitic fluid lipid profile among patients with ascites.

\section{Parameter}

Serum ascites Cholesterol gradient $(\mathrm{mg} / \mathrm{dL})$

Serum ascites Triglyceride gradient $(\mathrm{mg} / \mathrm{dL})$

Serum ascites HDL cholesterol gradient $(\mathrm{mg} /$ dL)

Serum ascites LDL cholesterol gradient $(\mathrm{mg} /$ $\mathrm{dL})$

$\mathrm{P}^{1}$-value: Cirrhosis versus tuberculosis.

$\mathrm{P}^{2}$-value: Cirrhosis versus malignancy.

$\mathrm{P}^{3}$-value: Tuberculosis versus malignancy.

* Statistically significant: $p$ value $<0.05$.

Table 5: Serum Ascites lipid gradient among patients with ascites.

\begin{tabular}{|c|c|c|c|c|c|}
\hline Cirrhosis $\mathbf{( n = 8 0 )}$ & Tuberculosis $\mathbf{( n = 2 0 )}$ & Malignancy $\mathbf{( n = 1 5 )}$ & $\mathbf{P}^{1}$-Value & $\mathbf{P}^{2}$-Value & $\mathbf{P}^{3}$-Value \\
\hline $97.9 \pm 28.6$ & $52.7 \pm 32.35$ & $49.4 \pm 28.64$ & $0.003^{*}$ & $0.002^{*}$ & 0.864 \\
\hline $74.7 \pm 28.2$ & $56.9 \pm 48.0$ & $48.3 \pm 29.23$ & $0.042^{*}$ & $0.001^{*}$ & 0.652 \\
\hline $28.67 \pm 9.11$ & $18.53 \pm 15.7$ & $14.7 \pm 14.8$ & $0.046^{*}$ & $0.02^{*}$ & 0.06 \\
\hline $55.7 \pm 26.1$ & $17.93 \pm 38.5$ & $28.5 \pm 13.65$ & $0.001^{*}$ & $0.002^{*}$ & 0.091 \\
\hline
\end{tabular}

and more physiological approach to classify ascites on the basis of presence or absence of portal hypertension [9,22,28]. Hoefs et al. [29] established a cutoff value of $1.1 \mathrm{~g} / \mathrm{dL}$, it was supported by various other studies $[9,22,28]$. Also, our study show similar results. SAAG can differentiate cirrhotic from non-cirrhotic ascites. If the SAAG is 1.1 $\mathrm{g} / \mathrm{dL}$ or greater the patient is considered to have portal hypertension. Conversely if the SAAG is $<1.1$ the patient is unlikely to have portal hypertension like tuberculosis. But according to the study by Lu CW et al. [30] SAAG was not as useful. Presently SAAG is included in the guidelines of investigations recommended on the management of ascites in cirrhosis by American Association of the Study of Liver Disease [AASLD] and British Society of Gastroenterology [1,2].

Our study disclosed that serum lipid profile (T.cholesterol, TG,
HDL, and LDL) decreases significantly in cirrhotic patients with ascites. The results of this study are similar with previous study by Ghadir and colleagues [31]. They reported that serum lipid profile was significantly lower in cirrhotic patients than the control group which is reasonably expected since liver biosynthesis has been reduced. Also, the present study is similar to studies from the western world which documented that all the lipid fragments in cirrhotic patients are lower than in control [32,33]. Sharatchandra et al. [24] reported that serum lipid profile was significantly lower in cirrhotic patients than tuberculous and malignant patients and our study show the same results.

Like SAAG, Serum Ascites Lipid Gradient (SALG) is also a subtraction of serum and ascitic fluid values of lipid fractions. Regarding the necessity of more evaluations about the association 


\begin{tabular}{|c|c|c|c|c|}
\hline Parameter & Child grade $(A)(n=9)$ & Child grade $(B)(n=21)$ & Child grade $(C)(n=50)$ & P-Value \\
\hline Serum ascites Cholesterol gradient (mg/dL) & $92.9 \pm 11.6$ & $95.6 \pm 22.35$ & $99.4 \pm 25.64$ & 0.892 \\
\hline Serum ascites Triglyceride gradient (mg/dL) & $70.7 \pm 32.2$ & $72.9 \pm 31.0$ & $76.3 \pm 33.6$ & 0.663 \\
\hline Serum ascites HDL cholesterol gradient $(\mathrm{mg} / \mathrm{dL})$ & $24.87 \pm 8.11$ & $26.43 \pm 11.9$ & $30.6 \pm 13.8$ & 0.762 \\
\hline Serum ascites LDL cholesterol gradient ( $\mathrm{mg} / \mathrm{dL}$ ) & $52.7 \pm 24.1$ & $54.93 \pm 39.8$ & $58.5 \pm 12.6$ & 0.943 \\
\hline
\end{tabular}

Table 6: Correlation between Serum Ascites lipid gradient levels and severity of cirrhosis.

\begin{tabular}{|c|c|c|}
\hline Parameter & Cut-off value (mg \%) & Sensitivity (\%) \\
\hline Serum ascites Cholesterol gradient & 67 & 90 \\
\hline Serum ascites Triglyceride gradient & 66 & 65 \\
\hline Serum ascites HDL cholesterol gradient & 26 & 62 \\
\hline Serum ascites LDL cholesterol gradient & 49 & 60 \\
\hline
\end{tabular}

Table 7: Cut-off values of SALG values, their sensitivity, and specificity.

between SALG and SAAG our study was designed to find a simple and cost effective test in order to differentiate between cirrhotic, malignant, and tuberculosis ascites. Few authors [34] have reported on SALG on cholesterol only. They have found the SALG (cholesterol) in cirrhotic, malignant, and tuberculous groups were $118.3 \pm 1.9,88.6 \pm 3.6$, and $56.5 \pm 2.6$ respectively. We have found SALG (cholesterol) values in cirrhosis, tuberculosis, and malignant group were $97.9 \pm 28.6,52.7 \pm$ 32.35 , and $49.4 \pm 28.64$ respectively. There was a significant difference between cirrhosis and tubercular or malignant ascites $(p<0.05)$. Our results were consistent with the study of Sharatchandra et al. [24]. Ascitic fluid cholesterol and SACG are better markers to differentiate malignant ascites from cirrhotic and tuberculous ascites [35] but in our study, Ascitic fluid cholesterol and SACG are better markers to differentiate cirrhotic ascites from tubercular or malignant ascites and this is contrary to Dharwadkar and Bijoor study who documented that SACG is not a good marker to differentiate tuberculous ascites and cirrhotic ascites [36].

In our study, the gradient was significantly higher in cirrhotic ascites compared to tuberculous and malignant ascites, in triglyceride ( $74.7 \pm 28.2$ versus $56.9 \pm 48.0$ and $48.3 \pm 29.23$ ), HDL cholesterol (28.67 \pm 9.11 versus $18.53 \pm 15.7$ and $14.7 \pm 14.8$ ), and LDL cholesterol (55.7 \pm 26.1 versus $17.93 \pm 38.5$ and $28.5 \pm 13.65)$ respectively in differentiating high albumin gradient ascites from low albumin gradient ascites. These results were consistent with the study of Sharatchandra et al. [24]. However, SALG was not superior to SAAG in our studied groups.

Portal hypertension in liver cirrhosis with ascites, though exactly not known, has been described to be related to many theories - thereby having a high hydrostatic pressure gradient between the portal bed and ascitic compartment. Interestingly, hypercholesterolaemia has been described in alcoholic liver cirrhosis [37]. However, an exact pathophysiological relationship between lipid gradients and portal hypertension is difficult to explain. It is hypothesized that there might be some factors related to lipid gradients which will indirectly reflect the abnormally high hydrostatic pressure gradient between the portal system and peritoneal compartment. On the other hand chylous ascites is most often the result of lymphatic obstruction from trauma, tumor, tuberculosis, filariasis, congenital abnormalities, or nephrotic syndrome; and rarely from liver cirrhosis. Our study showed significantly higher value of SALG for the portal hypertension group as compared to the other two groups without portal hypertension $(p<0.05)$. Malignant ascites had the lowest gradient among the three groups studied, for all parameters except for LDL. The cut-off SALG values being $67 \mathrm{mg} \%$, $66 \mathrm{mg} \%, 26$ and $49 \mathrm{mg} \%$ in cholesterol, triglyceride, HDL cholesterol, LDL cholesterol respectively in differentiating cirrhotic ascites from tuberculosis or malignant ascites and these results were near the study of Sharatchandra et al. [24].
In our study, A close relationship between the levels of SALG and severity of cirrhosis is found but it is not significant and to the best of our knowledge, no study has been done till date to address this topic.

\section{Conclusion}

SAAG is still the best marker to differentiate cirrhotic ascites from tuberculous or malignant ascites. SALG can be used as a screening test in ascitic patients as it may give clue to the possible etiology, and help in planning further investigative modalities in ascitic patients. In the present study SALG can be differentiate cirrhotic from tuberculous and malignant ascites. This is a simple and cost effective method for differentiation the etiology of ascites in developing countries.

\section{References}

1. Runyon BA (2004) Management of adult patients with ascites due to cirrhosis AASLD Practice Guideline. Hepatology 39: 1-16.

2. Moore KP, Aithal GP (2006) Guidelines on the management of ascites in cirrhosis. Gut 55 Suppl 6: vi1-12.

3. Paddock F (1940) The diagnostic signficance of serous fluids in Disease. New England Journal of Medicine 1940; 223: 1010.

4. Paré P, Talbot J, Hoefs JC (1983) Serum-ascites albumin concentration gradient: a physiologic approach to the differential diagnosis of ascites. Gastroenterology 85: 240-244.

5. Runyon BA (1993) Ascites and Spontaneous Bacterial Peritonitis. Sleisenge and Fordtran Gastrointestinal diseases. Philadelphia. WB Saunders 2: 1977 2003

6. Singh MM, Bhargava AN, Jain KP (1969) Tuberculous peritonitis. An evaluation of pathogenetic mechanisms, diagnostic procedures and therapeutic measures. N Engl J Med 281: 1091-1094.

7. Sood A, Garg R, Kumar R, Chhina RS, Arora S, et al. (1995) Ascitic fluid cholesterol in malignant and tubercular ascites. J Assoc Physicians India 43: 745-747.

8. Sampliner RE, Iber FL (1974) High protein ascites in patients with uncomplicated hepatic cirrhosis. Am J Med Sci 267: 275-279.

9. Rector WG Jr, Reynolds TB (1984) Superiority of the serum-ascites albumin difference over the ascites total protein concentration in separation of "transudative" and "exudative" ascites. Am J Med 77: 83-85.

10. Hoefs JC (1981) Increase in ascites white blood cell and protein concentrations during diuresis in patients with chronic liver disease. Hepatology 1: 249-254.

11. Runyon BA, Montano AA, Akriviadis EA, Antillon MR, Irving MA, et al. (1992) The Serum ascites albumin gradient is superior to the exudatetransudate concept in the differential diagnosis of ascites. Annal of Internal Medicine 117 215-20.

12. Jüngst $D$, Xie $Y$, Gerbes $A L$ (1992) Pathophysiology of elevated ascites fluid cholesterol in malignant ascites. Increased ascites to serum relation of proteins and lipoproteins in patients with peritoneal carcinomatosis as compared to patients with cirrhosis of the liver. J Hepatol 14: 244-248.

13. Jüngst D, Gerbes AL, Martin R, Paumgartner G (1986) Value of ascitic lipids 
Citation: Morsy KH, Ghaliony MAA, Mohamed HS, EIMelegy TTH (2014) Diagnostic Value of Serum Ascites Lipid Gradients in Patients with Ascites. J Liver 3: 165. doi:10.4172/2167-0889.1000165

Page 5 of 5

in the differentiation between cirrhotic and malignant ascites. Hepatology 6 : 239-243.

14. Garg R, Sood A, Arora S, Bhatia KL, Chawla AS, et al. (1993) Ascitic fluid cholesterol in differential diagnosis of ascites. J Assoc Physicians India 41 : 644-646.

15. Castaldo G, Oriani G, Cimino L, Topa M, Mostarda I, et al. (1994) Total discrimination of peritoneal malignant ascites from cirrhosis- and hepatocarcinoma-associated ascites by assays of ascitic cholesterol and lactate dehydrogenase. Clin Chem 40: 478-483.

16. Polack M, De Costa ACT, Bitelmann B (1978) Diagnostic value of the biochemical profile (protein, cholesterol, glucose, mucoprotein, amylase) of ascitic fluid. Rev Hosp Clin Fac Med S Paulo 33: 186-199.

17. Robert M Glickman (2005) Abdominal swelling and ascites. Casper DL, Braunwald E, Fauci AS, Hauser SL, Longo DL, Jameson JC. Harrison's Principles of Internal Medicine. NewYork. Mc Graw Hill publication 1: 243-245.

18. Dwivedi M, Misra SP, Misra V, Kumar R (1990) Value of adenosine deaminase estimation in the diagnosis of tuberculous ascites. Am J Gastroenterol 85 1123-1125.

19. Sood A, Garg R, Kumar R, Chhina RS, Arora S, et al. (1995) Ascitic fluid cholesterol in malignant and tubercular ascites. J Assoc Physicians India 43: 745-747.

20. Colloredo Mels G, Bellati G, Auriemma L, Perani C, Leandro G, et al. (1991) Fibronectin, cholesterol and triglycerides ascitic fluid concentration in the prediction of malignancy. Ital J Gastroenterol 23: 179-186.

21. Gerbes AL, Jüngst $D$, Xie YN, Permanetter W, Paumgartner G (1991) Ascitic fluid analysis for the differentiation of malignancy-related and nonmalignant ascites. Proposal of a diagnostic sequence. Cancer 68: 1808-1814.

22. Rector WG Jr (1987) An improved diagnostic approach to ascites. Arch Intern Med 147: 215

23. Rana SV, Babu SG, Kocchar R (2005) Usefulness of ascitic fluid cholesterol as a marker for malignant ascites. Med Sci Monit 11: CR136-142.

24. Sharatchandra LK, Ningsen R, Singh YI, Narendra RK, Ranjan S, et al. (2005) Serum Ascites Lipid Gradients in Alcoholic Liver Cirrhosis, Tuberculosis, and Malignancy. JIACM 6: 306-311.

25. Ranjith D, Ranjith MP, Dutta D, Krishnan MG, Rajendra K, et al. (2010) Ascitic fluid lipid profile and albumin level. Bangladesh Med Res Counc Bull 36: 34-37.

26. Friedewald WT, Levy RI, Fredrickson DS (1972) Estimation of the concentration of low-density lipoprotein cholesterol in plasma, without use of the preparative ultracentrifuge. Clin Chem 18: 499-502.

27. Menon VP, Jiandani PG, Chawla KP (1995) Ascitic fluid analysis--the yet new investigation. J Assoc Physicians India 43: 743-744.

28. Prieto M, Gómez-Lechón MJ, Hoyos M, Castell JV, Carrasco D, et al. (1988) Diagnosis of malignant ascites. Comparison of ascitic fibronectin, cholesterol, and serum-ascites albumin difference. Dig Dis Sci 33: 833-838.

29. Hoefs JC (1983) Serum protein concentration and portal pressure determine the ascitic fluid protein concentration in patients with chronic liver disease. J Lab Clin Med 102: 260-273.

30. Lu CW, Wang SS, Lee SD, Tsai YT, Lee FY, et al. (1991) Ascitic fluid analysis in peritoneal carcinomatosis: comparison of various biochemical tests with ascitic cirrhotics. Zhonghua Yi Xue Za Zhi (Taipei) 47: 350-356.

31. Ghadir MR, Riahin AA, Havaspour A, Nooranipour M, Habibinejad AA (2010) The relationship between lipid profile and severity of liver damage in cirrhotic patients. Hepat Mon 10: 285-288.

32. Cicognani C, Malavolti M, Morselli-Labate AM, Zamboni L, Sama C, et al. (1997) Serum lipid and lipoprotein patterns in patients with liver cirrhosis and chronic active hepatitis. Arch Intern Med 157: 792-796.

33. Siagris D, Christofidou M, Theocharis GJ, Pagoni N, Papadimitriou C, et al (2006) Serum lipid pattern in chronic hepatitis C: histological and virological correlations. J Viral Hepat 13: 56-61.

34. Gupta R, Misra SP, Dwivedi M, Misra V, Kumar S, et al. (1995) Diagnosing ascites: Value of ascitic fluid total protein, albumin, cholesterol, their ratios, serum ascites albumin and cholesterol gradient. J Gastroenterol and Hepato $10: 295-299$

35. Vyakaranam S, Nori S, Sastry M, Vyakaranam S B, Bhongir A V (2011) Serum Ascites Albumin and Cholesterol Gradients in Differential Diagnosis of Ascites. NJIRM 2: 22-28

36. Dharwadkar K, Bijoor AR (2013) Usefulness of Serum Ascites Cholestero Gradient (SACG), Total Protein (TP) ratio and Serum Ascites Albumin Gradient (SAAG) in differentiating tuberculous ascites and cirrhotic ascites. Int J Med Sci Public Health 2: 1068-1072.

37. Podolsky DK, Isselbacher KJ (2005) Cirrhosis and its complications. Caspe DL, Braunwald E, Fauci AS, Hauser SL, Longo DL, Jameson JC. Harrison's Principles of Internal Medicine. New York. Mc Graw Hill publication 2: 1858 1868. 